\title{
Is There Significant Difference between Digital and Glass Mercury Thermometer?
}

\author{
Hadgu Gerensea ${ }^{1}$ and Rajalakshmi Murugan ${ }^{2}$ \\ ${ }^{1}$ School of Nursing, College of Health Science, Axum University, P.O. Box 1010, Axum, Ethiopia \\ ${ }^{2}$ School of Nursing and Midwifery, Addis Ababa, Ethiopia \\ Correspondence should be addressed to Hadgu Gerensea; hadgugerensea2015@gmail.com
}

Received 30 September 2015; Revised 2 December 2015; Accepted 8 December 2015

Academic Editor: Ann M. Mitchell

Copyright (C) 2016 H. Gerensea and R. Murugan. This is an open access article distributed under the Creative Commons Attribution License, which permits unrestricted use, distribution, and reproduction in any medium, provided the original work is properly cited.

Background. Children's decisions concerning investigation and treatment may be based on the results of temperature alone. Although the accuracy of axillary temperature measurement is affected by a number of factors, device dwell time and device type are common. Objective. Compare body temperature between glass mercury thermometer (GMT) and digital thermometer (DT). Method. Comparative descriptive study was used. A total of 101 samples were taken with convenient sampling technique, but 98 were analyzed. Statistical significance $(p<0.01)$ and clinical significance $\left(\mathrm{MD} \geq 0.2^{\circ} \mathrm{C}\right)$ were used in the analyses. Correlations and Bland-Altman plots were used to observe agreements of the recording. Results. Mean difference (MD) of 10 min GMT and DT was $0.13 \pm 0.11$. Statistically significant differences were noted in $10 \mathrm{~min}$ GMT and DT $(p<0.00)$. But the correlations were strong positive $(r>0.75)$ and all MD were at the limit of agreement in Bland-Altman plot. Clinically, it is not significant $\left(\mathrm{MD}<0.2^{\circ} \mathrm{C}\right)$. Conclusion and Recommendations. Even though statistical significant differences $(p<0.001)$ were noted between 10 min GMT and DT, the strong correlation, good agreements, and clinical insignificances make DT good alternative to the traditional GMT. Their variation in temperature is not likely to change any clinical decision. So, health professionals should use DT for measuring body temperature in under-5 febrile illnesses.

\section{Introduction}

1.1. Background and Statement of the Problem. Body temperature is a measure of the body's ability to generate and get rid of heat. The normal physiology is to keep body temperature within a narrow safe range in spite of large variations in environmental temperatures [1]. Maintenance of body temperature occurs through the integration of multiple body systems that interact to maintain a balance between heat loss and generation. Normal body temperature is around $37^{\circ} \mathrm{C}\left(98.6^{\circ} \mathrm{F}\right)$ but varies during the day. The lowest body temperature occurs in early morning hours ( 2 am to 4 am) and the highest temperature occurs in the late afternoon. Body temperature may also increase as a result of overdressing or strenuous exercise, especially in hot weather [2].

Febrile illness is defined as a disease characterized by an increase of body temperature more than $37.5^{\circ} \mathrm{C}$ resulting from infectious process. Febrile illnesses (FIs) due to different etiologic agents are the most common causes of morbidity and mortality in developing tropical and subtropical countries [3].

Many of the infectious diseases assessed, classified, and treated using the Integrated Management of Childhood Illnesses (IMCI) guidelines have fever as a secondary cause. For example, many children with upper respiratory tract infection, pneumonia, or ear infection will have fever. Severe illnesses associated with danger signs are also associated with fever, such as sepsis septicemia and meningitis. The danger signs lead to appropriate referral for the illness. Fever is also associated with malaria, dysentery, and diarrhea in children. In these patients, the cause of the fever is treated and fever is not used in decision making. While these conditions all cause fever, the management of the condition itself results in the management of the fever [4].

A thermometer is a device that measures temperature or temperature gradient, using a variety of principles. For recording body temperature, several different types of thermometers are used, such as mercury thermometers, 


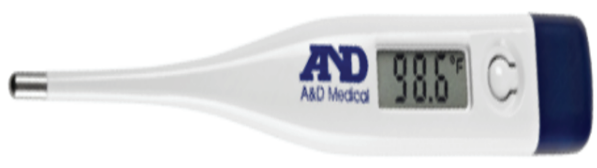

Digital thermometer

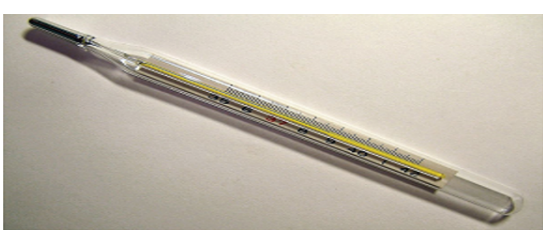

A clinical mercury-in-glass thermometer

Glass mercury

FIGURE 1: Digital and glass mercury thermometer.

digital thermometer, liquid crystal forehead thermometer, and infrared tympanic thermometer [1]. Observe glass mercury and digital thermometers in Figure 1.

Body temperature in children can be measured at a number of anatomical sites using a range of different types of thermometers, including mouth, rectum, and axilla [5]. Ideally, measurement should be reliable, noninvasive, nontraumatic, culturally acceptable, user friendly, and hygienic. Since rectal temperature measurements are relatively more time-consuming, invasive, uncomfortable, less hygienic, and unacceptable in many cultures, and oral temperature is unhygienic and difficult in children, axillaries measurements have been the method of choice in many countries [6-8].

Evaluation of body temperature is one of the oldest known diagnostic methods and is still an important sign of health and disease, both in everyday life and in medical care. The individual can describe feelings of illness and discomfort, but in conditions where individuals are unable to explain themselves, for example, children, the nurse has to interpret the clinical signs and rely on objective measurements [9]. Change in body temperature is one of the most important physical sign and symptom in both acute febrile illness and chronic illnesses in children. This is especially important in newborns, in which fever can be indicative of infection. It was shown that temperature out of the normal range is closely related to the survival of infants $[6,7,10,11]$. Many decisions concerning the investigation and treatment of children may be based on the results of temperature measurement alone $[12,13]$.

As the basic sciences develop, temperature measurement methods and devices were improved. For hundreds of years, both in clinics and in home, GMT was the standard of human temperature measurements [14] and currently developing countries are using it commonly [15] though it is no longer recommended [11, 13, 16-19]. DTs are widely used by healthcare professionals as an alternative to GMT as they are faster and easier to read and avoid the environmental concerns of mercury $[5,19]$.

Although accuracy of axillary temperature measurement is affected by a number of factors, including ambient temperature, local blood flows, inappropriate placing of the probe, closure of the axillary cavity, and device dwell time, device type is common which can led to false high readings which may lead to expensive and painful diagnostic studies and medical interventions or false low readings which may lead to greater morbidity and mortality. So, temperature measurement must be accurate and consistent, as decisions about therapeutic intervention are based on it [9, 20-24].

The accuracy of devices to record and grade temperature is uncertain [1]. Limited researches have addressed whether the thermometer correctly identifies patients with hyperthermia or hypothermia. In general, these studies indicate that noninvasive temperature measurements are accurate in ruling out hyperthermia and hypothermia, but they may fail to detect hyperthermia and hypothermia, depending on the thermometer used. In particular, there is controversy in alternative approach of digital to mercury thermometers regarding accuracy and sensitivity [25]. So, this study may address the gap among health professionals.

1.2. Rationale and Significance of the Study. Temperature taking is the most frequently performed clinical observation and is predominantly a nursing task. Although the use of digital thermometer is gradually increasing, GMT is still the most common device used in the pediatric setting, especially in developing countries [15] in spite of having long dwelling time, danger of breakage, potential harm and toxic vapor effects; difficulties in reading, and possible role in spread of hospital acquired infections [11, 13, 16-19, 26].

Current nursing studies on temperature measurement are conducted to understand the efficacy of the various types of equipment available to measure temperature [2729], but they are insufficient and contradictory [30]. In particular, there is debate between GMT and DT regarding their accuracy in measuring true body temperature and their ability to detect fever and hypothermia. Researches on those devices are scarce besides the manufacturer's data sheets. Even the little documented studies have large discrepancy and health professionals are in debate. Due to inconsistencies in both research methods and clinical practice [31,32], nurses are challenging in selecting the measurement method that is most appropriate for a patient and provides the most accurate and precise approximation of core temperature [33].

The false low and false high result related to accuracy of thermometer device and dwelling time may lead to misdiagnosis and treatment. If DTs are to become the standard device used in the clinical setting, they must be subjected to rigorous investigations to increase the knowledge of practitioner and thereby improve practice.

Febrile illnesses are the most common leading cause of morbidity and mortality in under- 5 children which needs accurate measurement of body temperature. Ethiopia is one 
of the developing countries which use both GMT and DT in measuring body temperature with the uncertainty of the device and dwelling time in their capability of detecting hyperthermia and hypothermia. So, it is important to know the standard time and accurate device to measure body temperature.

This study fills the gaps among health professionals and has some input on nursing body of knowledge. It will have contribution for decision makers and significant others to take possible measure on temperature measurement device. It may decrease misdiagnosis of febrile illness in under-5 children related to inaccuracy of body temperature measurement due to devices type. This study will also be used as a base line data for further research on comparison of temperature measuring devices related topics. It is designed to investigate whether DT is suitable alternative to GMT in children.

1.3. Research Questions. Can digital thermometer be used as alternative device with old standard GMT in axillary site in under-5 children with febrile illness?

\section{Objectives}

Compare body temperature between 10 min glass mercury and digital thermometers among under-5 children with febrile illness at axillary site in Axum Saint Mary Hospital.

\section{Methodology}

3.1. Study Area. The study was carried out in Axum, city of northern Ethiopia, $1024 \mathrm{Km}$ north of Addis Ababa and $241 \mathrm{Km}$ far from Mekelle which is the capital city of Tigray region, located in the Central Zone of Tigray Region near the base of the Adwa mountains and surrounded by La'ilay Maychew woreda. Axum was the original capital of the kingdom of Axum and one of the oldest continuously inhabited places in Africa. Saint Marry Hospital is one of the 13 governmental hospitals found in Tigray region which serve medical care for Axum's population and nearby. In Tigray region $16.9 \%$ of the population is under-5 years and Axum town have around 7,490 numbers of children less than five years according to city administration report in 2012 [34].

St. Marry Hospital is one of the referral hospitals in the zone in which FI is prevalent. At the time of my clinical experience, nurses working in the hospital and clinical students was debated regarding the devices even the controversy was as national. Since accurate diagnoses of FI were needed hospital were best than health center. This was why the study focused on this area. Similarly as the generalizability was to the devices, study area may not have effect.

3.2. Study Period. The Study was conducted from November/2013 to May/2014. The data was collected from 2129/4/2014 G.C.

3.3. Study Design. Comparative descriptive study design was used to compare body temperature between GMT and digital thermometer among under-5 children with FI at axillary site in Axum St. Marry Hospital.

\subsection{Source and Study Population}

3.4.1. Source Population. The source population was all under-5 age children with FI visiting Axum St. Marry Hospital for healthcare service.

3.4.2. Study Population. The study population was under5 children with FI visiting Axum St. Marry Hospital for healthcare service, particularly in under-5 OPD.

\subsection{Inclusion and Exclusion Criteria}

3.5.1. Inclusion Criteria. Inclusion criteria were children under 5 years of age with FI visiting Axum St. Mary Hospital particularly under-5 OPD at the time of data collection

3.5.2. Exclusion Criteria. Patients with local infection in axilla, lethargy, or unconscious were excluded. Irritable subjects were also excluded.

3.6. Sample Size Determination. A total of 96 samples were calculated using the mean difference of $10 \mathrm{~min}$ GMT and DT (0.27) and SD 0.54 and 0.42 (pooled SD $=0.484)$ at alpha of 0.01 with detection capability (power) of $90 \%$ (beta 0.1 ) and taking 1 as ratio of exposed to nonexposed using open Epi statistical software. 5\% of 96 were added so the total of 101 study subjects were taken. But 3 were discarded in the analysis because of incompleteness and being unreadable. Manually, the study was also calculated using the following formula:

$$
\begin{aligned}
N & =\frac{(r+1)\left(Z_{\alpha / 2}+Z_{1-\beta}\right)^{2} \sigma^{2}}{r d^{2}}, \\
N & =\frac{(1 \pm 1)(2.58 \pm 1.28)^{2} * .4837^{2}}{1 * .27^{2}} \\
& =\frac{2 * 14.9 * 0.234}{1 * .073}=\frac{6.972}{0.073} \\
& =95.5 \sim 96+5 \% \text { of } 96=101,
\end{aligned}
$$

where " $r$ " was the ratio of control to experimental which is $1: 1$ so $r=1$, " $\delta$ " is the pooled SD: $0.4837, d$ is the mean difference, 0.27 , and $N$ is the sample for each group. " $Z_{1-\beta}$ " was normally deviated at $90 \%: 1.28$, and " $Z_{\alpha / 2}$ " was for $1 \%$ which is 2.58 .

3.7. Sampling Procedures. A convenient sampling technique was used as the study has no frame. Since axillary movement exposes the mercury thermometer to the environment, which was easily affected by environmental temperature, children who were irritable were purposely excluded from the study. All under-5 children with FI visiting under-5 OPD of St. Marry Hospital fulfilling the inclusion criteria were taken until the sample size reaches 101 . 


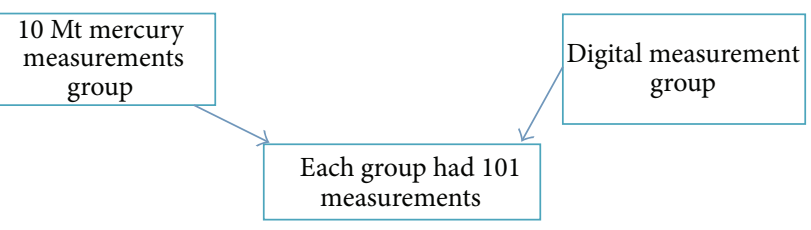

Figure 2: Diagrammatic presentation of comparison of body temperature among under-5 children.

3.8. Clinical Study Procedures. Study participants were under 5 years of age and body temperature was not increased or decreased intentionally.

GMT and DT were on right and left axillaries, respectively, which are selected by lottery method for the first study subject. After that, GMT and DT were exchanged with consecutive study subjects for right and left axillaries. For details, see Figure 2.

3.9. Data Collection Procedures (Instrument, Personnel, and Data Quality Control). The study continuously collected primary data through data collection tool which was developed after review of literatures and consultation of experts in nursing (Professor Asrat, Dr. Amsal, and Professor Brhane). For content validity, the tool was reviewed. The tool included Part I: demographic preforma and Part II: recording temperature result and observation checklist. The demographic performa was filled before starting the procedures.

All data collectors (B.S. nurses) were screened for test of visual acuity in both eyes 6/6 and trained thoroughly with close supervision for 4 days in correct positioning, calibration, reading of thermometers, and documentation based on WHO guideline of taking axillary temperature. All the temperatures were measured on Celsius $\left({ }^{\circ} \mathrm{C}\right)$ scale and timed with the same stop clock except for digital which have beep sound.

The validity and reliability of GMT and DT were cheeked in ICU adult who are measured by core temperature measurement prior to data collection. By marking the least valid GMT and DT, all thermometers were left for $5 \mathrm{~min}$ in water bath three times. Of these, the four thermometers gave the same value. Of the $5 \mathrm{GMT}$ and DT, $3 \mathrm{GMT}$ and $3 \mathrm{DT}$ were used. 2 GMT and DT were excluded. The comparisons were done for the same devices only.

This study was performing measurements following manufacturer information for each of the thermometry instruments as described in the instruments and measurements section.

\subsection{Variables}

3.10.1. Dependent Variables. The dependent variables were accuracy of body temperature result.

\subsubsection{Independent Variables}

Temperature Variation Variables. Device type (GMT, DT)and dwelling time of GMT (5 min and $10 \mathrm{~min}$ ) were the study variables.
Covariant Variables. Route of measurement, right and lift axilla, placement of probe, environment, local blood flow, closure of axilla, taking antipyretic medication, taking bath within $30 \mathrm{~min}$, time (morning, afternoon), and type of FI were the covariant variables.

3.11. Scale of Measurements. For body temperature, degree Celsius scale of measurement was used in both GMT and DT. For time in GMT, minute was scale of measurement, whereas beep sound was used in DT.

3.12. Data Analysis Procedures. First, the data were entered and coded to Epi info version 3.5.4 and exported to SPSS version 21 of Window 7 for analyses. Descriptive statistics was used to describe participants' demographic characteristics and temperature result (hypothermia, normal, pyrexia, and hyperpyrexia) by percentage, mean, standard deviation, and range. Correlation was determined by Pearson correlation coefficient (to determine the strength of the correlation) while the extent of agreement was assessed with BlandAltman plot. To determine statistically significant difference, a paired $t$-tests was used. $p<0.01$ was considered statistically significant. Not only statistical but also clinical significance was also considered in the analyses. Even though the standard clinical significance varies with different literatures, most of them use a mean difference of $0.2^{\circ} \mathrm{C}$ and above as clinical significance [35-37]. This study also used mean difference of $0.2^{\circ} \mathrm{C}$ and above as clinical significance.

3.13. Data Quality Management. Examination of visual acuity was given for data collectors. Similarly, training for data collectors was given. Content validity was checked by experts. Pretest was conducted on 10 children in under-5 OPD of Axum health center. After this pretest, some modifications were incorporated. Close supervision during data collection procedures and proper recordings were also taken. Immediate checkup was carried out and any unfulfilled data was filled immediately.

3.14. Ethical Considerations. Institution Review Board (IRB) of Addis Ababa University, College of Health Science, School of Allied Health Sciences, Department of Nursing and Midwifery, reviewed the protocol to insure full protection of the rights of study subjects. Following the approval by IRB, official letter of cooperation was written to Axum St. Marry Hospital from the Department of Nursing and Midwifery of AAU. After getting permission from Axum St. Marry Hospital, data collectors informed parents verbally and at least one parent was present during the data collection. Data was treated confidentially and subject were identified by number only. Since it is axillary, it is safe and measurements were taken at OPD during assessment. It took $15 \mathrm{~min}$ to take all measurements for one study subject. So, it has no treatment and investigation delay. As the sampling is convenience, irritable subjects were not also forced. Risk of skin irritation was informed with informed consent. Any breakage of GMT was disposed to be appropriate as it is environmental hazard. Probe was cleaned according to service manual instructions 
TABLE 1: Sociodemographic characteristics of under-5 children with febrile illnesses in under-5 OPD.

\begin{tabular}{|c|c|c|c|c|}
\hline S. number & & Variables & Frequency $(n=98)$ & Percentage (\%) \\
\hline \multirow{4}{*}{1} & \multirow{4}{*}{ Age } & $0-28$ days & 4 & 4.1 \\
\hline & & 29 days- 1 years & 30 & 30.6 \\
\hline & & $1-3$ years & 34 & 34.7 \\
\hline & & $3-5$ years & 30 & 30.6 \\
\hline \multirow{2}{*}{2} & \multirow{2}{*}{ Sex } & Male & 45 & 45.9 \\
\hline & & Female & 53 & 54.1 \\
\hline \multirow{2}{*}{3} & \multirow{2}{*}{ Religion } & Orthodox & 90 & 91.8 \\
\hline & & Muslim & 8 & 8.2 \\
\hline \multirow{4}{*}{4} & \multirow{4}{*}{ Care giver } & Mother & 86 & 87.8 \\
\hline & & Father & 7 & 7.1 \\
\hline & & Sister/brother & 2 & 2 \\
\hline & & Care servant & 3 & 3.1 \\
\hline \multirow{2}{*}{5} & \multirow{2}{*}{ Data collection time } & Morning & 66 & 67.3 \\
\hline & & Afternoon & 32 & 32.7 \\
\hline \multirow{2}{*}{6} & \multirow{2}{*}{ Taking antipyretic within $30 \mathrm{~min}$} & Yes & 8 & 8.2 \\
\hline & & No & 90 & 91.8 \\
\hline \multirow{2}{*}{7} & \multirow{2}{*}{ Taking bath within $30 \mathrm{~min}$} & Yes & 2 & 2 \\
\hline & & No & 96 & 98 \\
\hline
\end{tabular}

(Welch Allyn, Inc.) prior to use for individual study subject as this prevents risk of infection.

\section{Result and Discussion}

\subsection{Result}

4.1.1. Sociodemographic Characteristics. A total one hundred and one study subjects were included in the study, but ninetyeight $(97 \%)$ of them were analyzed. three were excluded because of their incompleteness and being unreadable. Sixtysix $(67.3 \%)$ were collected in the morning. Fifty-three $(54.1 \%)$ were female. Thirty-four $(34.7 \%)$ of the children aged from 1 to 3 years. Ninety (91.8\%) and 96 (98\%) were not taking antipyretic and bath $30 \mathrm{~min}$ prior to temperature measurements, respectively. For further details, see Table 1.

Most of the under- 5 children in the study were diagnosed with pneumonia which accounts for 35 (35.7\%). For further details, see Figure 3.

4.1.2. Temperature Differences between $10 \mathrm{~min}$ GMT and DT. In this study, one reading was for 10 min glass mercury thermometer and digital thermometer for each study subject. The procedure was carried out for 98 subjects. This resulted in 98 temperature readings for each $10 \mathrm{~min}$ GMT and digital thermometer. The mean temperature of $10 \mathrm{~min}$ GMT and digital was $37.30 \pm 0.78$. See Table 2 .

The maximum and minimum difference of $10 \mathrm{~min}$ mercury and DT was $0.4^{\circ} \mathrm{C}$ and $0.1^{\circ} \mathrm{C}$, respectively. But 19 have no difference.

Only $13(13.3 \%)$ of the 98 paired measurements of each 10 min GMT and DT had temperature difference greater than $0.2^{\circ} \mathrm{C}$, respectively. For further details, see Table 3 .

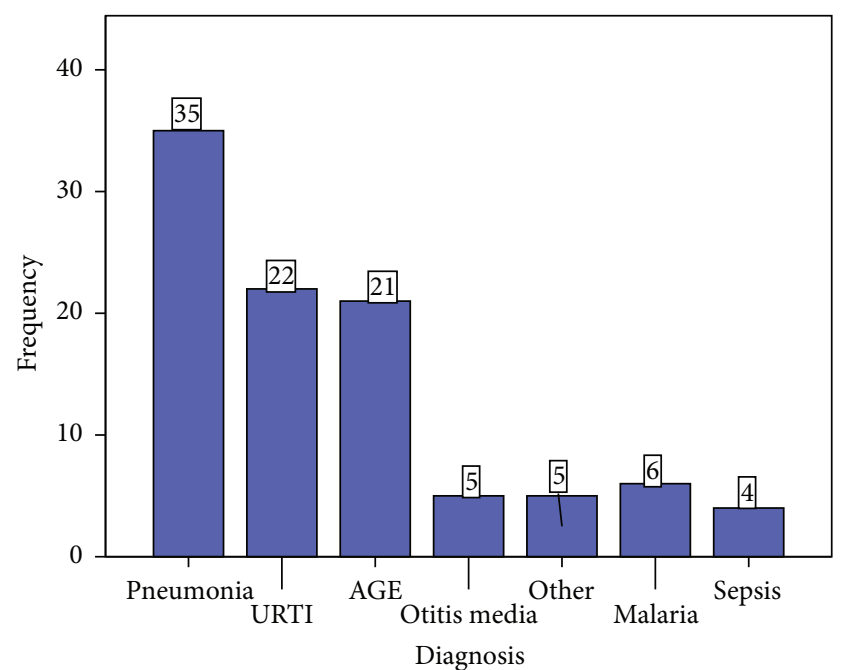

FIGURE 3: Diagnosis of under-5 children with febrile illnesses in under-5 OPD.

44 outof 98 measurments were resulted in normal temperature by GMT and DT. For further details, see Table 4.

The mean difference of $10 \mathrm{~min}$ GMT and DT was 0.12857 \pm 0.10745 .

4.1.3. Correlation Analyses between $10 \mathrm{~min}$ GMT and DT. 10 min GMT has strong positive correlation with DT. The Pearson correlation $(r)$ of 10 min GMT and DT was 0.99 which implies the fact that as the result of $10 \mathrm{~min}$ GMT increases, the result of DT also increases. Both have direct positive relation (Table 5 and Figure 4). 
TABLE 2: Mean, SD, and range of temperature results of 10 min glass mercury and digital thermometers.

\begin{tabular}{lcccccc}
\hline Thermometers & Observation & Mean \pm SD & Median & Range & Minimum & Maximum \\
\hline 10 min mercury & 98 & $37.43 \pm 0.77$ & 37.4 & 3.7 & 35.9 & 39.6 \\
Digital & 98 & $37.30 \pm 0.78$ & 37.3 & 3.6 & 35.8 & 39.4 \\
\hline
\end{tabular}

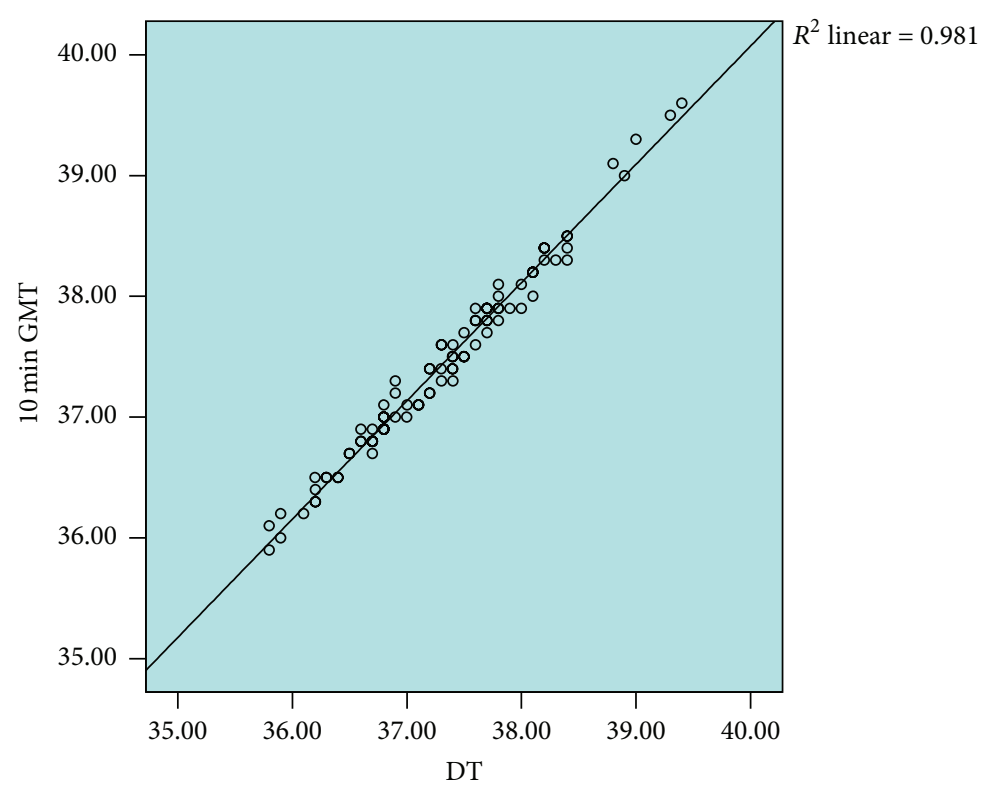

FIGURE 4: Correlation of 10 min glass-mercury and digital thermometers.

TABLE 3: Frequency of the difference of temperature in ${ }^{\circ} \mathrm{C}$ between 10 min glass mercury and digital thermometers.

\begin{tabular}{lcc}
\hline Comparisons & $\begin{array}{c}\text { Difference of } \\
\text { temperature in }{ }^{\circ} \mathrm{C}\end{array}$ & $\begin{array}{c}\text { Frequency of } \\
\text { difference } n(\%)\end{array}$ \\
\hline 10 min mercury & No & $19(19.4)$ \\
and digital & 0.1 & $38(38.8)$ \\
thermometers & 0.2 & $\mathbf{2 8}(\mathbf{2 8 . 5})^{*}$ \\
& $>0.2$ & $\mathbf{1 3 ( 1 3 . 3 ) ^ { * }}$ \\
\hline
\end{tabular}

The bold and “*” indicate the frequency of clinical significant.

4.1.4. Paired t-Test and Bland-Altman Analyses between $10 \mathrm{~min}$ $G M T$ and $D T$. Statistically significant mean differences were noted in comparisons of temperatures of 10 min GMT with DT $(p<0.00)$, but there were no clinical differences (defined as a mean difference of $0.2^{\circ} \mathrm{C}$ ). For details, see Table 6 .

Mean differences of $10 \mathrm{~min}$ GMT and DT in relation to sociodemographic and other factors were done. But no clinically significant mean difference was observed (Table 7).

In order to determine the concordance between GMT and DT, the Bland-Altman method of analysis was used.

Figure 5 represents Bland-Altman plot of the $10 \mathrm{~min}$ mercury temperature readings and the digital temperature readings. On $x$-axis, the mean of the mercury and the digital temperature is plotted, and on $y$-axis the difference between the temperature readings of $10 \mathrm{~min}$ mercury and digital thermometer is plotted. In this plot, a line of mean difference

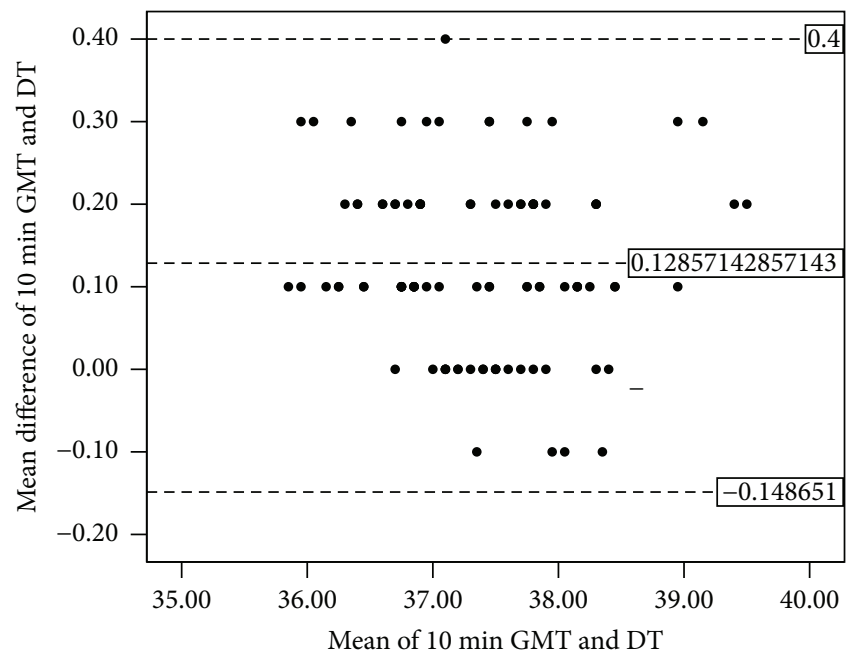

FIGURE 5: Bland-Altman plot of 10 min glass mercury and digital thermometers.

and the lines of $99 \%$ limits of agreements are presented. All of the readings were falling within the lines of limits of agreement, that is, upper limit of 0.4 and lower limit of -0.1487 .

The horizontal line in the middle indicates the mean difference of two measurements, and two additional lines indicate $2.58 * \mathrm{SD}$ above and below the mean (upper and lower limit of agreement) 
TABLE 4: Frequency of grading fever by thermometers.

\begin{tabular}{lcccc}
\hline \multirow{2}{*}{ Thermometers } & \multicolumn{3}{c}{ Frequency (percentage) of grading of fever } \\
& Hypothermia & Normal & Pyrexia & Hyperpyrexia \\
\hline 10 min mercury & $8(8.2)$ & $44(44.9)$ & $46(46.9)$ & $0(0)$ \\
Digital & $13(13.3)$ & $44(44.9)$ & $41(41.8)$ & $0(0)$ \\
\hline
\end{tabular}

Hypothermia $\left(<36.5^{\circ} \mathrm{C}\right)$; normal $\left(36.5-37.5^{\circ} \mathrm{C}\right)$; pyrexia $\left(37.5-40^{\circ} \mathrm{C}\right)$; hyperpyrexia $\left(40^{\circ} \mathrm{C}\right.$ and above).

TABLE 5: Correlation between 10 minute glass mercury and digital thermometers.

\begin{tabular}{lcc}
\hline Thermometers & 10 min GMT & DT \\
\hline 10 min GMT & 1 & \\
DT & 0.99 & 1 \\
\hline
\end{tabular}

Figure 5 shows 10 min GMT was higher in 75 individuals than DT. Similarly, DT was higher in 4 individuals than 10 min GMT as DT was subtracted from 10 min GMT.

10 min GMT and DT was agreed on in 88 of 98 measurements (For further details, see Table 8).

4.2. Discussion. Due concerns about the breakages and environmental hazards of digital thermometers have evolved with the hope of replacing the glass mercury thermometer. The importance of the speed of application and the ease of use of DT is important in busy clinical area, but accuracy must be a primary concern.

The present study was conducted to find the concordance of the digital thermometer with the glass mercury thermometer with the hypothesis that there are statistical significant mean differences in temperature result between 10 min GMT and DT.

The participant characteristics of this study were under-5 children who had febrile illness unlike the study conducted in Turkey (healthy infants and healthy young students aged from 18 to 24), India (health neonates), and Malaysia (all age group with illness) $[19,27,38]$. Similarly, this study measured temperature at auxiliary which was consistent with other studies in Turkey, India, and Korea, [19, 27, 39], but not with Malaysia which was on oral site [38]. Most of the previous studies used only statistical test $[36,39-48]$ unlike this study, which used both statistical and clinical implications in the overall decision of the research hypothesis.

The mean difference of 10 min GMT and DT in this study showed a statistical significance $(p<0.00)$. This finding was supported from the study of Biomedical Instrumentation and Technology which indicates that the improvements in safety, speed, and simplicity of use of the DT have been offset by statistically significant difference. Latman states that "the current generation of electronic, digital clinical thermometers, in general, may not be sufficient to replace the traditional glass/mercury thermometers" [49].

But from the point of clinical importance, the mean difference (0.13) of $10 \mathrm{~min}$ and DT of this study was not of clinical significance. $99 \%$ of the mean differences were between 0.10 and 0.16 , which are not clinically significant. The correlation also showed strong positive correlation $(r=0.99)$ and all the mean differences were also falling in the limit of the agreement. These results were similar to the studies conducted in Iran and USA in which digital thermometers gave the best concordance with mercury thermometers [18, $50,51]$.

The variation of temperature between $10 \mathrm{~min}$ GMT and DT was not homogeneous (consistent). Furthermore, the mean difference observed between 10 min GMT and DT was not clinically significant, so no compensation for the differences was needed.

But one study found that GMT and DT were clinically and statistically significant with mean difference of 0.278 and $p>0.05$ [38]. This difference might be because of the route difference, since the study was conducted in oral route in which GMT were highly influenced by ingestion of food prior to $30 \mathrm{~min}$. Similarly, the measurements were not taken simultaneously unlike this study.

4.2.1. Conclusion. Even though a statistical significance $(p<$ 0.00 ) difference was observed between $10 \mathrm{~min}$ GMT and DT, their mean differences were not clinically significant $\left(<0.2^{\circ} \mathrm{C}\right)$ or do not differ enough to cause problems in clinical interpretation. Their correlations were also strong positive correlation $(r>0.75)$ and all the mean differences among them were falling in the limit of agreement in BlandAltman plot. Their variation in temperature is not likely to change any clinical decision. No compensation for the difference is needed since lack of consistent mean differences (homogeneous variations) between GMT and DT was shown. Similarly, their differences were clinically not significant.

Statistically, the alternative hypothesis was not rejected. But this statistical significance cannot prejudice the alternative approach of DT because the clinical insignificances observed were most important (the primary concern).

Generally, the strong correlations, good agreements, and clinical insignificances observed make DT good alternative to the traditional GMT. Similarly, some important disadvantages of GMT, such as danger of breakage, potential harm and toxic vapor effects, difficulties in reading the values on the device, possible role in spread of hospital acquired infection, and long dwelling time, and advantage of DT, such as rapid result delivery, improved patient comfort, being an easy and noninvasive procedure, also support this alternative approach. Therefore,

(i) health professionals should use DT for measuring body temperature in under-5 febrile illnesses as it has no clinical significance difference with GMT and has some advantages over GMT (being easy to 
TABLE 6: Mean differences between comparison groups.

\begin{tabular}{lcccc}
\hline Comparison groups & Mean difference \pm SD & $t$-cal. & $p$ value & \multicolumn{2}{c}{$\begin{array}{c}99 \% \text { CI of the mean difference } \\
\text { Upper }\end{array}$} \\
\hline 10 min GMT and DT & $0.13 \pm 0.11$ & 11.85 & $\mathbf{0 . 0 0}$ & 0.10 \\
\hline
\end{tabular}

TABLE 7: Comparison groups in relation to sociodemographic and other variables.

\begin{tabular}{|c|c|c|c|c|}
\hline \multirow{2}{*}{$\mathrm{SN}$} & \multirow{2}{*}{ Sociodemographic and other variables } & \multirow{2}{*}{ Observation } & \multicolumn{2}{|c|}{10 min GMT and digital } \\
\hline & & & $\mathrm{MD} \pm \mathrm{SD}$ & $p$ value \\
\hline \multirow[t]{5}{*}{1} & Age & & & \\
\hline & $0-28$ days & 4 & $0.10 \pm 0.16$ & 0.31 \\
\hline & 29 days-1 year & 30 & $0.14 \pm 0.10$ & 0.00 \\
\hline & $1-3$ years & 34 & $0.13 \pm 0.11$ & 0.00 \\
\hline & $3-5$ years & 30 & $0.13 \pm 0.10$ & 0.00 \\
\hline \multirow[t]{3}{*}{2} & Time of measurement & & & \\
\hline & Morning & 67 & $0.12 \pm 0.11$ & 0.00 \\
\hline & Afternoon & 31 & $0.14 \pm 10$ & 0.00 \\
\hline \multirow[t]{3}{*}{3} & Taking antipyretic & & & \\
\hline & Yes & 8 & $0.16 \pm 0.12$ & 0.01 \\
\hline & No & 90 & $0.13 \pm 0.10$ & 0.00 \\
\hline \multirow[t]{3}{*}{4} & Axillary & & & \\
\hline & Rt GMT and Lt DT & 49 & $0.13 \pm 0.10$ & 0.00 \\
\hline & Lt GMT and Rt DT & 49 & $0.12 \pm 10$ & 0.00 \\
\hline
\end{tabular}

TABLE 8: Agreement of 10 min glass mercury with digital thermometers in specific range of temperature.

\begin{tabular}{|c|c|c|c|c|}
\hline \multicolumn{2}{|c|}{$10 \min \mathrm{GMT}$} & \multicolumn{3}{|c|}{$\begin{array}{l}\text { Digital thermometers } \\
\text { Temperature results in }{ }^{\circ} \mathrm{C}\end{array}$} \\
\hline & & $<36.5$ & $36.5-37.5$ & $\geq 37.5$ \\
\hline \multirow{3}{*}{$\begin{array}{l}\text { Temperature } \\
\text { results in }{ }^{\circ} \mathrm{C}\end{array}$} & $<36.5$ & 8 & 0 & \\
\hline & $36.5-37.5$ & 5 & 39 & 0 \\
\hline & $\geq 37.5$ & 0 & 5 & 41 \\
\hline
\end{tabular}

Key and Clinical implications: the numerical value represents the number of recordings in each category. The bold values represent agreement for that specific temperature range.

read, having fast result, and being environmentally friendly) $[5,19]$;

(ii) researchers should further study the instruments in neonates as clinical significance is different from the present study and the age groups were few. Similarly, the sensitivity may differ from other since their skin integrity is different. Likewise, their concordance in detecting hypothermia should be investigated since the sensitivity may differ;

(iii) Moreover, researchers should repeat the study by using core temperature as the gold standard for comparison since comparison of DT with GMT may have additive effect of deviation from core temperature;

(iv) FMHACA should focus on DT rather than GMT as it has no clinical significance difference with GMT and have some advantages over GMT (being easy to read, having fast result, and being environmentally friendly) $[5,19]$.

\section{Conflict of Interests}

The authors declare that there is no conflict of interests regarding the publication of this paper.

\section{Acknowledgments}

The authors are very grateful and would like to extend their heartfelt thanks and appreciation to the study participants and data collectors for their full participation and for supporting data collection. Finally, they would like to acknowledge Addis Ababa University, College of Health Sciences, School of Allied Health Sciences, Department of Nursing and Midwifery, for giving them this great opportunity.

\section{References}

[1] N. Rahman, F. B. Kasem, M. R. Islam, M. R. Islam, R. Sultana, and A. Matin, "Comparison between mercury and liquid crystal forehead thermometers for measurment of body temperature," Journal of Shaheed Suhrawardy Medical College, vol. 4, no. 2, pp. 60-61, 2012.

[2] B. J. Holtzclaw, "Circadian rhythmicity and homeostatic stability in thermoregulation," Biological Research for Nursing, vol. 2, no. 4, pp. 221-235, 2001.

[3] A. B. Woyessa, W. Ayele, A. Ahimed, and A. Nega, "Investigation of acute febrile illness outbreak-Asyaita and Dupti districts, Afar Region, Ethiopia, February 2011," Retrovirology, vol. 9, supplement 1, article P46, 2012. 
[4] World Health Organization (WHO) Department of Child and Adolescent Health and Development (CAH), Technical Seminar-Other Causes of Fever, pp. 1-5.

[5] D. Ng, J. Lam, and K. Chow, "Childhood fever revisited," Hong Kong Medical Journal, vol. 8, no. 1, article 39, 2002.

[6] Ö. Çultu, I. Yildirim, M. Ceyhan et al., "Comparing body temperature measurements by mothers and physicians using mercury-in-glass, digital mercury and infrared tympanic membrane thermometers in healthy newborn babies," Turkish Journal of Pediatrics, vol. 50, no. 4, pp. 354-358, 2008.

[7] J. D. Zeal, ThermoSpot-A Non-Invasive Hypothermia Indicator for Neonates, Infants and Children, Camborne Consultants, 1999.

[8] M. Adhi, R. Hasan, F. Noman, S. F. Mahmood, A. Naqvi, and A. U. Rizvi, "Range for normal body temperature in the general population of Pakistan," Journal of Pakistan Medical Association, vol. 58, no. 10, pp. 580-584, 2008.

[9] M. Sund-Levander, Measurement and evaluation of body temperature, implications for clinical practice [Ph.D. thesis], 2004.

[10] J. Bailey and P. Rose, "Axillary and tympanic membrane temperature recording in the preterm neonate: a comparative study," Journal of Advanced Nursing, vol. 34, no. 4, pp. 465-474, 2001.

[11] W. Chung and C. Chen, "Evaluation of performance and uncertainty of infrared tympanic thermometers," Sensors, vol. 10, no. 4, pp. 3073-3089, 2010.

[12] A. S. El-Radhi and W. Barry, "Thermometry in paediatric practice," Archives of Disease in Childhood, vol. 91, no. 4, pp. 351356, 2006.

[13] F. M. Fadzil, D. Choon, and K. Arumugam, "A comparative study on the accuracy of noninvasive thermometers," Australian Family Physician, vol. 39, no. 4, pp. 237-239, 2010.

[14] I. Devrim, A. Kara, M. Ceyhan et al., "Measurement accuracy of fever by tympanic and axillary thermometry," Pediatric Emergency Care, vol. 23, no. 1, pp. 16-19, 2007.

[15] N. Benkovich, B. C. Farrell, A. Nimunkar, J. Baran, and J. G. Webster, Low Cost Digital Thermometer, 2009.

[16] R. Dolkar, S. Kapoor, N. V. Singh, and V. Suri, "A comparative study on the recording of temperature by the clinical mercury thermometer and digital thermometer," Nursing and Midwifery Research, vol. 9, no. 1, pp. 40-46, 2013.

[17] G. I. Gasim, I. R. Musa, M. T. Abdien, and I. Adam, "Accuracy of tympanic temperature measurement using an infrared tympanic membrane thermometer," BMC Research Notes, vol. 6, no. 1, article 194, 2013.

[18] ByadMton, Ed., Best Infant Thermometers, Tympanic Thermometersk, 2013.

[19] M. Yvonne and B. Shevchuk, "Fever," in Therapeutic Choices for Minor Ailments, chapter 9, pp. 85-92, Canadian Pharmacists Association, 2013.

[20] I. Pušnik and A. Miklavec, "Dilemmas in measurement of human body temperature," Instrumentation Science and Technology, vol. 37, no. 5, pp. 516-530, 2009.

[21] T. Schmitz, N. Bair, M. Falk, and C. Levine, "A comparison of five methods of temperature measurement in febrile intensive care patients," American Journal of Critical Care, vol. 4, no. 4, pp. 286-292, 1995.

[22] L. McCallum and D. Higgins, "Measuring body temperature," Nursing Times, vol. 108, no. 45, pp. 20-22, 2012.

[23] J. Grady, Nursing Procedure: Measuring and Monitoring Temperature in the Highly Dependent or Critically Ill Infant or ChildAxilla Temperature Review, NHS, 2015.
[24] L. S. Smith, "ReexaMting age, race, site, and thermometer type as variables affecting temperature measurement in adults-a comparison study," BMC Nursing, vol. 2, no. 1, article 1, 2003.

[25] E. Bridges and K. Thomas, "Noninvasive measurement of body temperature in critically ill patients," Critical Care Nurse, vol. 29, no. 3, pp. 94-97, 2009.

[26] H. M. Rosenthal and A. Leslie, "Measuring temperature of NICU patients-a comparison of three devices," Journal of Neonatal Nursing, vol. 12, no. 4, pp. 125-129, 2006.

[27] L. Khorshid, İ. Eşer, A. Zaybak, and Ü. Yapucu, "Comparing Mercury-in-glass, tympanic and disposable thermometers in measuring body temperature in healthy young people," Journal of Clinical Nursing, vol. 14, no. 4, pp. 496-500, 2005.

[28] A. Sganga, R. Wallace, E. Kiehl, T. Irving, and L. Witter, "A comparison of four methods of normal newborn temperature measurement," MCN: The American Journal of Maternal/Child Nursing, vol. 25, no. 2, pp. 76-79, 2000.

[29] S. Uslu, H. Ozdemir, A. Bulbul et al., "A comparison of different methods of temperature measurements in sick newborns," Journal of Tropical Pediatrics, vol. 57, no. 6, pp. 418-423, 2011.

[30] G. G. Arslan, I. Eser, and L. Khorshid, "Analysis of the effect of lying on the ear on body temperature measurement using a tympanic thermometer," Journal of the Pakistan Medical Association, vol. 61, no. 11, pp. 1065-1068, 2011.

[31] S. Cassandra Sutton, Year 2 Issue: Oral Versus Axilla Temperature Measurement [A Review of the Evidence], Tasmanian School of Nursing Nuritinga, Tasmania, Australia, 1999.

[32] S. P. Davies, J. Y. Kassab, A. J. Thrush, and P. H. Smith, "A comparison of mercury and digital clinical thermometers," Journal of Advanced Nursing, vol. 11, no. 5, pp. 535-543, 2006.

[33] L. Lawson, E. J. Bridges, I. Ballou et al., "Accuracy and precision of noninvasive temperature measurement in adult intensive care patients," American Journal of Critical Care, vol. 16, no. 5, pp. 485-496, 2007.

[34] Wikipedia, "National Statistics-population-2011 by town and sex," 2011.

[35] P. Fulbrook, "Core temperature measurement in adults: a literature review," Journal of advanced nursing, vol. 18, no. 9, pp. 1451-1460, 1993.

[36] N. E. McKenzie, "Evaluation of a new, wearable, precision phase-change thermometer in neonates," Pediatric Nursing, vol. 29, no. 2, pp. 117-125, 2003.

[37] R. J. Yetman, D. K. Coody, M. S. West, D. Montgomery, and M. Brown, "Comparison of temperature measurements by an aural infrared thermometer with measurements by traditional rectal and axillary techniques," The Journal of Pediatrics, vol. 122, no. 5, pp. 769-773, 1993.

[38] D. Chaturvedi, K. Y. Vilhekar, P. Chaturvedi, and M. S. Bharambe, "Comparison of axillary temperature with rectal or oral temperature and determination of optimum placement time in children," Indian Pediatrics, vol. 41, no. 6, pp. 600-603, 2004.

[39] B. N. Jensen, F. S. Jensen, S. N. Madsen, and K. Lossl, "Accuracy of digital tympanic, oral, axillary, and rectal thermometers compared with standard rectal mercury thermometers," European Journal of Surgery, vol. 166, no. 11, pp. 848-851, 2000.

[40] G. Greyling, M. J. Viljoen, and G. Joubert, "Axillary temperature compared to tympanic membrane temperature in children," Curationis, vol. 23, no. 3, pp. 54-61, 2000.

[41] A. Deorari, "Neonatal hypothermia," in Newborn Care Practice and Care Settings; State of India's Children, pp. 65-71, NNF India, New Delhi, India, 2004. 
[42] J. I. He, "The study on different time to take temperature in axillary," Friend of Chemical Industry, no. 29, pp. 20-21, 2009.

[43] L. Sheng, C. Heping, and Z. Qinfang, "Probe into measuring time of auxillary temperature for patients," Chinese General Nursing, vol. 33, article 002, 2008.

[44] S.-Y. Li, Mt. Lin, and C.-H. Huang, "Research and practice of axillary temperature measurement at interval," Journal of Henan University (Medical Science), vol. 31, no. 1, pp. 53-54, 2012.

[45] J. V. Craig, G. A. Lancaster, P. R. Williamson, and R. L. Smyth, "Temperature measured at the axilla compared with rectum in children and young people: systematic review," The British Medical Journal, vol. 320, no. 7243, pp. 1174-1178, 2000.

[46] N. J. Shanks, A. Lambourne, C. Morton, and J. R. A. Sanford, "Comparison of accuracy of digital and standard mercury thermometers," British Medical Journal, vol. 287, no. 6401, article 1263, 1983.

[47] S. P. Davies, J. Y. Kassab, A. J. Thrush, and P. H. Smith, "A comparison of mercury and digital clinical thermometers," Journal of Advanced Nursing, vol. 11, no. 5, pp. 535-543, 1986.

[48] R. Kitsommart and S. Phatthanasiriwetin, "Accuracy and precision of digital thermometer in neonatal temperature measurement," Siriraj Medical Journal, vol. 57, no. 5, pp. 126-130, 2005.

[49] N. S. Latman, P. Hans, L. Nicholson, S. Delee Zint, K. Lewis, and A. Shirey, "Evaluation of clinical thermometers for accuracy and reliability," Biomedical Instrumentation \& Technology, vol. 35, no. 4, pp. 259-265, 2001.

[50] R. Imani, S. Salehi, R. Habibian, B. Sadeghi, and K. Hatamipour, "Comparative study of measuring body temperature by mercury and digital thermometer," Iran Journal of Nursing, vol. 21, no. 56, pp. 9-16, 2009.

[51] M. S. Chand, "A comparative study on difference in the manual and electronic recording of vital signs in patients admitted in CTVS-ICU and CCU of advanced cardiac center at PGIMER," vol. 11, 2010. 


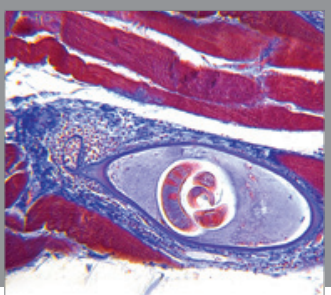

Gastroenterology

Research and Practice
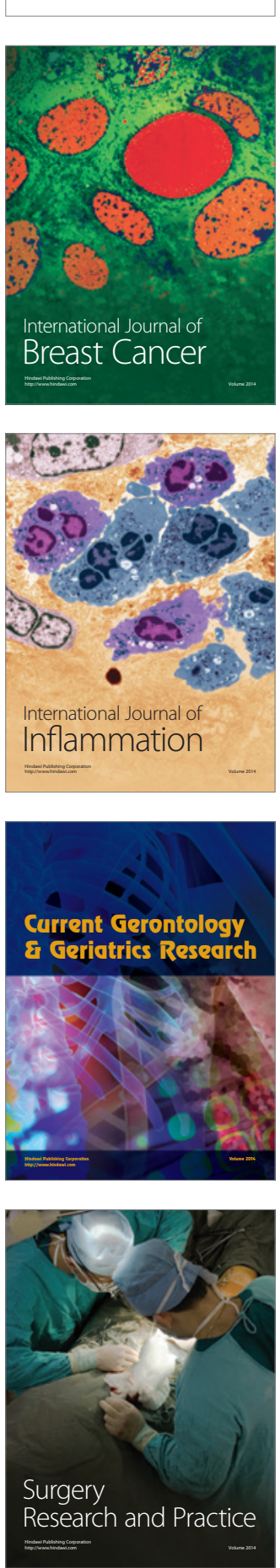

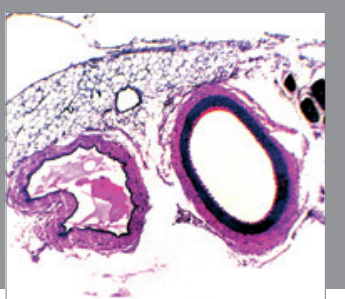

International Journal of Hypertension
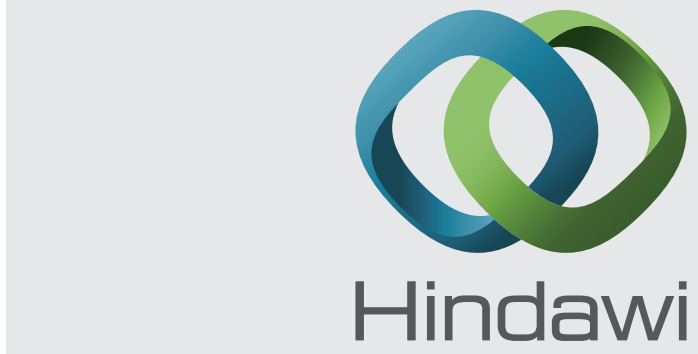

Submit your manuscripts at http://www.hindawi.com
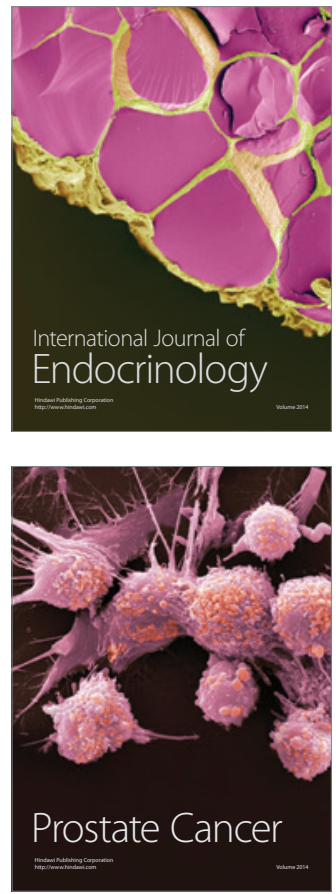

The Scientific World Journal
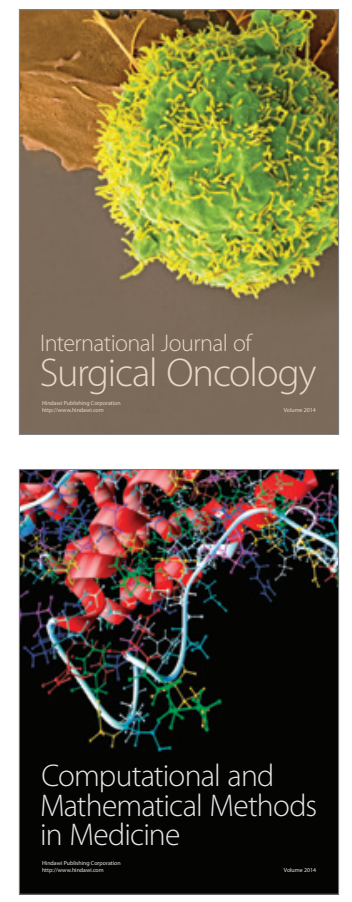
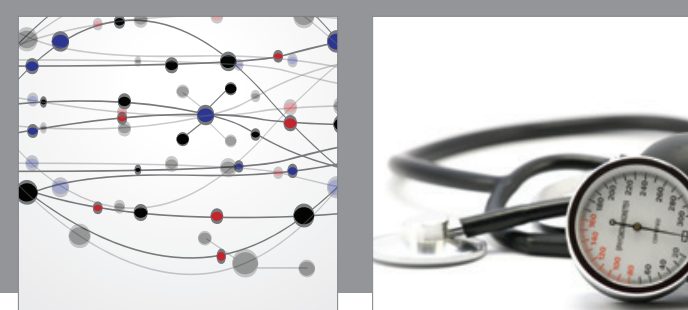

Nursing

Research and Practice

Research and Practice
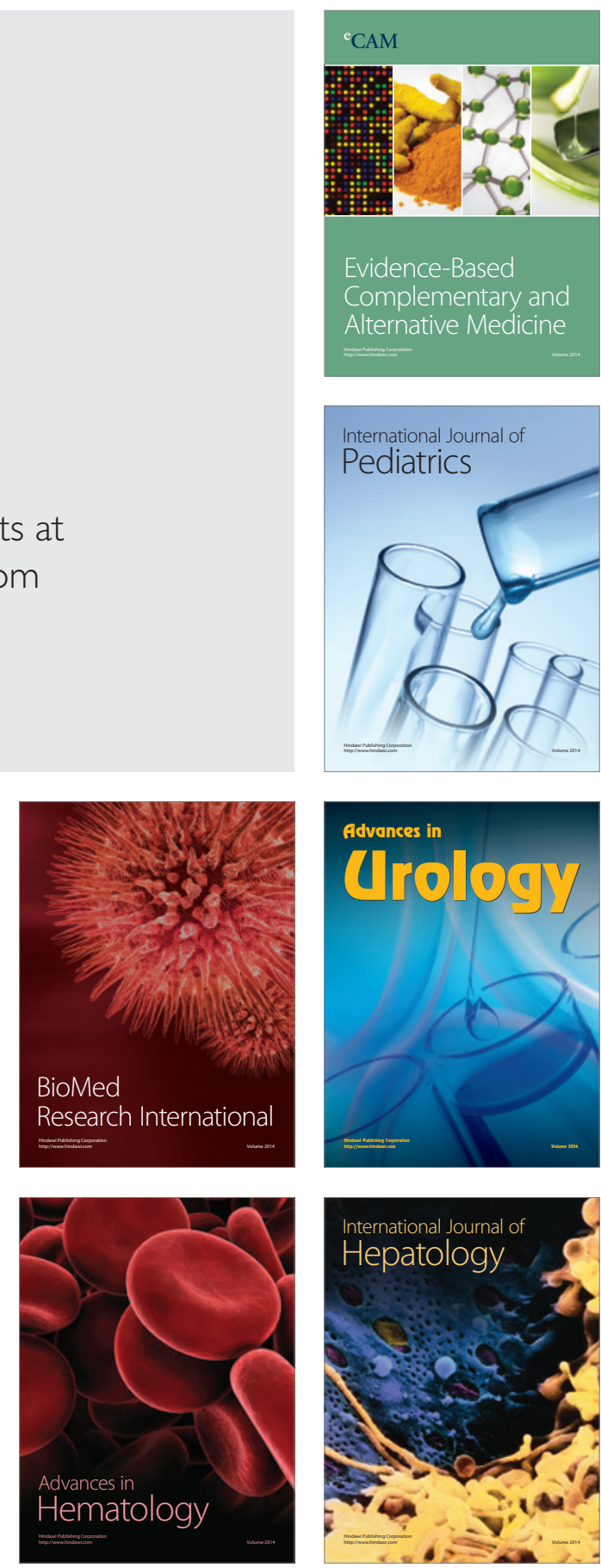
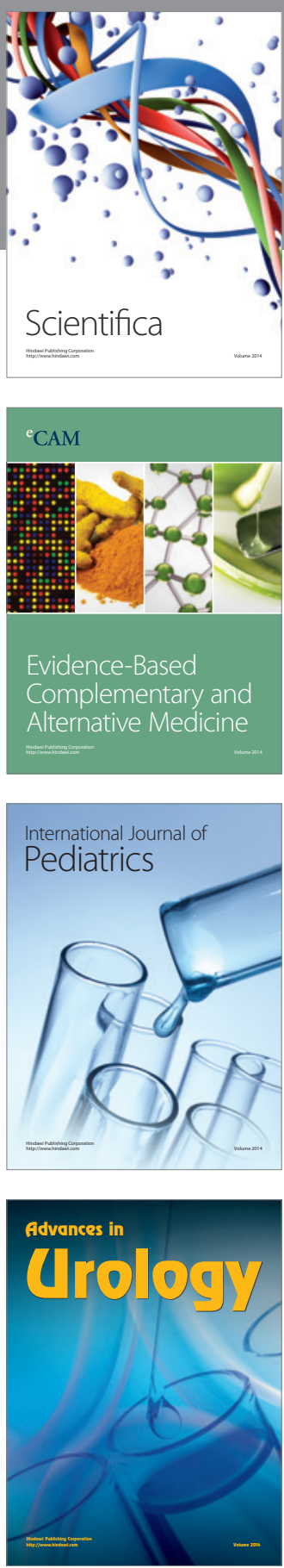

Scientifica

Evidence-Based

Complementary and

Alternative Medicine

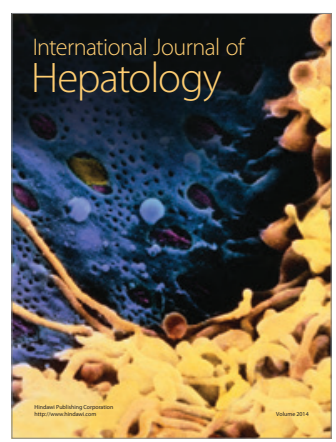

